\title{
Diabetes and the risk of hospitalisation for infection: the Atherosclerosis Risk in Communities (ARIC) study
}

\author{
Michael Fang ${ }^{1,2}$. Junichi Ishigami ${ }^{1,2}$ • Justin B. Echouffo-Tcheugui ${ }^{3} \cdot$ Pamela L. Lutsey $^{4} \cdot$ James S. Pankow $^{4}$. \\ Elizabeth Selvin ${ }^{1,2}$
}

Received: 26 March 2021 / Accepted: 20 May 2021 / Published online: 4 August 2021

(C) The Author(s), under exclusive licence to Springer-Verlag GmbH Germany, part of Springer Nature 2021

\begin{abstract}
Aims/hypothesis The aim of this work was to assess the association between diabetes and risk for infection-related hospitalisation and mortality.

Methods We conducted a prospective cohort analysis of the Atherosclerosis Risk in Communities (ARIC) study. Diabetes was defined as a fasting glucose $\geq 7 \mathrm{mmol} / 1$ or non-fasting glucose $\geq 11.1 \mathrm{mmol} / \mathrm{l}$, self-report of a diagnosis of diabetes by a physician, or current diabetes medication use. Hospitalisation for infection was ascertained from hospital discharge records. Participants were followed from 1987-1989 to 2019.

Results We included 12,379 participants (mean age 54.5 years; 24.7\% Black race; $54.3 \%$ female sex). During a median followup of 23.8 years, there were 4229 new hospitalisations for infection. After adjusting for potential confounders, people with (vs without) diabetes at baseline had a higher risk for hospitalisation for infection (HR 1.67 [95\% CI 1.52, 1.83]). Results were generally consistent across infection type but the association was especially pronounced for foot infection (HR 5.99 [95\% CI $4.38,8.19])$. Diabetes was more strongly associated with hospitalisation for infection in younger participants and Black people. Overall infection mortality was low (362 deaths due to infection) but the adjusted risk was increased for people with diabetes (HR $1.72[95 \%$ CI $1.28,2.31])$.

Conclusions/interpretation Diabetes confers significant risk for infection-related hospitalisation. Enhancing prevention and early treatment of infection in those with diabetes is needed to reduce infection-related morbidity and mortality.
\end{abstract}

Keywords Diabetic complications · Disparities · Infection hospitalisation · Infection mortality · Longitudinal analyses

\section{Abbreviations \\ ARIC Atherosclerosis Risk in Communities \\ COVID-19 Coronavirus disease-2019 \\ SES Socioeconomic status}

Elizabeth Selvin

eselvin@jhu.edu

1 Department of Epidemiology, Johns Hopkins Bloomberg School of Public Health, Baltimore, MD, USA

2 Welch Center for Prevention, Epidemiology and Clinical Research, Johns Hopkins Bloomberg School of Public Health, Baltimore, MD, USA

3 Division of Endocrinology, Diabetes and Metabolism, Department of Medicine, Johns Hopkins School of Medicine, Baltimore, MD, USA

4 Division of Epidemiology and Community Health, University of Minnesota, Minneapolis, MN, USA

\section{Introduction}

Diabetes is widely thought to increase susceptibility to infection by impairing neutrophil functioning, antioxidant systems and humoral immune response [1,2]. Consistent with this hypothesis, diabetes is associated with an increased risk of common and rare infections [1, 3, 4]. However, most studies examined small clinical populations and were cross-sectional or had short follow-up [3]. Few large, prospective studies have investigated the link between diabetes and future risk of infection-related outcomes in the general population [5-9].

Guidelines for diabetes management focus on the prevention of micro- and macrovascular complications and pay less attention to infectious diseases $[10,11]$. Clarifying the role of diabetes in infection risk is an urgent public health concern. 


\section{Research in context}

\section{What is already known about this subject?}

- Diabetes is widely thought to increase susceptibility to infection-related outcomes

- Prior studies have largely focused on small clinical populations and have had short follow-up

- Few large, prospective studies have investigated the link between diabetes and future risk of infectionrelated outcomes in the general population

\section{What is the key question?}

- Is diabetes associated with an increased risk for infection-related hospitalisation or mortality in the general population?

\section{What are the new findings?}

- Diabetes was independently associated with an increased risk of infection-related hospitalisation and mortality

- The association between diabetes and hospitalisation for foot infection was particularly pronounced

- Diabetes was more strongly associated with hospitalisation for infection in younger participants and Black people

\section{How might this impact on clinical practice in the foreseeable future?}

- Current guidelines for infection prevention and management for people with diabetes are limited; our study suggests that more comprehensive guidance is necessary to reduce infection-related morbidity and mortality in individuals with diabetes

From 2000 to 2015, the overall rate of hospitalisation from infections in US adults rose significantly, especially in people with diabetes [10]. More recently, diabetes has emerged as an important risk factor for adverse outcomes in coronavirus disease-2019 (COVID-19) and may be a risk factor for infection from severe acute respiratory syndrome coronavirus-2 (SARS-CoV-2), the virus that causes COVID-19 [12, 13]. Thus, our objective was to examine the associations between diabetes and risk of hospitalisation for infection and mortality due to infection in the Atherosclerosis Risk in Communities (ARIC) study.

\section{Methods}

Study sample We analysed data from the ARIC study, an ongoing community-based cohort designed to examine the aetiology of atherosclerotic disease. The study was comprised of 15,792 adults aged 45-64 years from four US communities: Forsyth County, NC; Jackson, MS; suburbs of Minneapolis, MN; and Washington County, MD. Participants were recruited in 19871989 for clinical examinations, medical interviews and laboratory tests (visit 1). Subsequent study visits were conducted in 1990-1992 (visit 2), 1993-1995 (visit 3), 1996-1998 (visit 4), 2011-2013 (visit 5), 2016-2017 (visit 6) and 2018-2019 (visit 7). All participants provided written informed consent and the study was approved by institutional review boards at all research sites. Further details about the ARIC study are available elsewhere [14].

Visit 1 was the baseline for our current study. We excluded respondents with missing information for diabetes status and covariates. Because of small sample size, we also excluded those with a race other than Black or White and excluded Black adults in Minneapolis, MN, or Washington County, MD. These restrictions yielded an analytical sample of 12,379 respondents.

Diabetes status During study visits, participants self-reported if they had ever been diagnosed with diabetes by a physician. They brought in all prescription medications used over the prior 2 weeks and had plasma glucose measured using the hexokinase method. We defined diabetes at baseline as fasting glucose $\geq 7 \mathrm{mmol} / \mathrm{l}$, non-fasting glucose $\geq 11.1 \mathrm{mmol} / 1$, selfreport of a diagnosis of diabetes by a physician, or use of glucose-lowering medication at study visit 1 . Because no antibody testing was performed, we could not distinguish between type 1 and type 2 diabetes in our analyses.

Hospitalisation for infection and infection mortality The ARIC study conducted continuous active surveillance of hospitalisations for all participants. We defined first hospitalisation for infection as an infection ICD-9-CM/ICD- 
10-CM code (www.icd9data.com/2007/Volume1/default.htm and http://apps.who.int/classifications/icd10/browse/2016/en, respectively) in the first diagnostic position from hospital discharge records (ESM Table 1). Diagnostic codes were derived from prior ARIC studies focused on infectionrelated hospitalisation [15], along with research specifically focused on infection in individuals with diabetes [10]. We considered first hospitalisation for specific diabetes-related infections (respiratory, urinary, foot, gastrointestinal, sepsis and postoperative wound) as secondary outcomes (ESM Table 1) [10].

Vital status was determined through linkage to the National Death Index, telephone interviews with participant proxies and review of state records. We defined infection mortality as an infection ICD-9-CM/ICD-10-CM code (ESM Table 1) listed as the underlying cause of death in death certificates.

We calculated person-time from study visit 1 until the first hospitalisation for infection (for hospitalisation for infection analysis only), death due to infection (for infection mortality analysis only), loss to follow-up, or administrative censoring, whichever came first. The final day of follow-up was 31 December 2017 for participants at one research site (Jackson, MS) and 31 December 2019 for all other participants.

Information on covariates Structured questionnaires were administered at baseline to collect information on respondents' demographic characteristics (age, sex, race, study centre, health insurance status, household income, education level) and health behaviours (smoking, alcohol consumption). Race and study centre were combined into a single measure (race-centre) to account for the uneven distribution of Black and White participants across research sites. Area deprivation was derived by combining 17 different neighbourhood socioeconomic status (SES) measures (e.g. median family income of a neighbourhood) into an index based on 2000 Census data [16]. Categories of participants' annual household income (0, $>\$ 50,000 ; 1, \$ 25,000-\$ 49,999 ; 2, \$ 12,000-\$ 24,999 ; 3$, $<\$ 12,000)$, education level (0, graduate/professional school; 1 , college with or without completion; 2 , high school/general educational development/vocational school; 3, <high school) and area deprivation ( 0 , lowest area deprivation quartile, lowest deprivation; 3 , highest quartile, highest deprivation) were summed to create a SES score (high, 0-2; medium, 36; low, $\geq 7$ ).

BMI was calculated as weight ( $\mathrm{kg}$ ) divided by height $(\mathrm{m})$ squared. Obesity status was defined as either being obese $\left(\right.$ BMI $\geq 30 \mathrm{~kg} / \mathrm{m}^{2}$ ) or non-obese (BMI $<30 \mathrm{~kg} / \mathrm{m}^{2}$ ). HDLcholesterol and triacylglycerol levels were measured using enzymatic methods. LDL-cholesterol was calculated using the Friedewald equation. Hypertension was defined as BP $\geq 140 / 90 \mathrm{mmHg}$ or self-reported use of BP-lowering medication. eGFR was determined using the Chronic Kidney Disease Epidemiology Collaboration formula [17]. Chronic kidney disease was defined as eGFR $<60 \mathrm{ml} \mathrm{min}^{-1}[1.73 \mathrm{~m}]^{-2}$. Prevalent CHD was defined by self-reported prior diagnosis or cardiovascular revascularisation, or evidence of a myocardial infarction on a study ECG.

Statistical analysis We examined differences in participant characteristics at baseline by diabetes status using $\chi^{2}$ or $t$ tests to assess group differences. We estimated the age-adjusted rate of hospitalisation for infection and infection mortality using predictive margins from Poisson models with robust error variance [18], using follow-up time as an offset. We used Cox proportional hazard models to examine the associations between diabetes and risk of hospitalisation for infection and infection mortality. We evaluated three models: model 1 included age, sex, race-centre; model 2 included all variables in model 1 plus SES score, health insurance status, smoking and alcohol consumption; model 3 included all variables in model 2 plus BMI, hypertension, chronic kidney disease, prevalent CHD status, HDL-cholesterol, triacylglycerols and LDL-cholesterol. In exploratory analyses, we examined potential effect modification by age, sex, race, SES, health insurance status and obesity status using Wald tests.

In sensitivity analyses, we examined the risk for hospitalisation for infection with diabetes measured as a time-varying exposure. We assessed the association between diabetes and incident hospitalisation for infection while accounting for the competing risk of death using the FineGray model. We estimated the rate of total hospitalisation for infection (including recurrent events) using Poisson models.

We performed all analyses using Stata 16.0 (StataCorp, College Station, TX, USA). A two-sided $p$ value of $<0.05$ was considered statistically significant.

\section{Results}

We included 12,379 participants (mean age 54.5 years; $24.7 \%$ Black race; $54.3 \%$ female sex). Participants with diabetes at baseline were more likely to be older, to be Black, and to have a low SES and worse cardiometabolic health (Table 1).

During a median follow-up of 23.8 years, there were 4229 incident hospitalisations for infection (Table 2). The overall rate of hospitalisation for infection was 15.9 per 1000 personyears. Compared with those without diabetes at baseline, those with diabetes had a greater risk for hospitalisation for infection (25.4 vs 15.2 per 1000 person-years). After adjusting for sociodemographic characteristics, the HR was 1.92 (95\% CI 1.76, 2.09) for those with diabetes at baseline (model 1). Differences were slightly attenuated after adjusting for SES, health insurance and health behaviours (model 2, HR 1.88 [95\% CI 1.72, 2.05]). Adjusting for cardiometabolic factors (model 3) further reduced differences, though a significant 
Table 1 Baseline characteristics of participants by diabetes status (the ARIC study, 1987-1989)

\begin{tabular}{|c|c|c|c|c|}
\hline Characteristic & $\begin{array}{l}\text { Overall } \\
(N=12,379)\end{array}$ & $\begin{array}{l}\text { No diabetes } \\
(n=10,894)\end{array}$ & $\begin{array}{l}\text { Diabetes } \\
(n=1485)\end{array}$ & $\begin{array}{l}p \\
\text { value }^{\mathrm{a}}\end{array}$ \\
\hline \multicolumn{5}{|l|}{ Demographics } \\
\hline Age, years & $54.5 \pm 5.7$ & $54.3 \pm 5.7$ & $55.8 \pm 5.6$ & $<0.001$ \\
\hline Age $\geq 55$ years & 49.9 & 48.5 & 60.0 & $<0.001$ \\
\hline Female sex & 54.3 & 54.3 & 54.4 & 0.92 \\
\hline Race (centre) & & & & $<0.001$ \\
\hline White (Forsyth County, NC, USA) & 22.7 & 23.6 & 16.0 & \\
\hline White (Minneapolis, MN, USA) & 26.4 & 27.8 & 16.5 & \\
\hline White (Washington, MD, USA) & 26.2 & 26.4 & 25.2 & \\
\hline Black (Forsyth County, NC, USA) & 3.2 & 2.9 & 5.1 & \\
\hline Black (Jackson, MS, USA) & 21.5 & 19.4 & 37.2 & \\
\hline SES & & & & $<0.001$ \\
\hline Low & 22.9 & 20.3 & 41.3 & \\
\hline Middle & 41.9 & 42.2 & 39.5 & \\
\hline High & 35.2 & 37.4 & 19.1 & \\
\hline No health insurance & 9.3 & 8.4 & 15.7 & $<0.001$ \\
\hline \multicolumn{5}{|l|}{ Health behaviours } \\
\hline Drinking status & & & & $<0.001$ \\
\hline Current drinker & 56.5 & 59.0 & 38.2 & \\
\hline Former drinker & 19.5 & 18.2 & 28.9 & \\
\hline Never drinker & 24.0 & 22.8 & 32.9 & \\
\hline Cigarette smoking status & & & & 0.005 \\
\hline Current smoker & 27.0 & 27.4 & 23.8 & \\
\hline Former smoker & 32.5 & 32.5 & 32.6 & \\
\hline Never smoker & 40.5 & 40.1 & 43.6 & \\
\hline \multicolumn{5}{|l|}{ Cardiometabolic factors } \\
\hline Hypertension & 35.5 & 32.1 & 60.1 & $<0.001$ \\
\hline Obesity & 27.6 & 24.4 & 50.8 & $<0.001$ \\
\hline Chronic kidney disease & 1.4 & 1.0 & 3.9 & $<0.001$ \\
\hline Prevalent CHD & 5.2 & 4.5 & 10.6 & $<0.001$ \\
\hline HDL-cholesterol, mmol/1 & $1.33 \pm 0.44$ & $1.35 \pm 0.44$ & $1.17 \pm 0.38$ & $<0.001$ \\
\hline Triacylglycerols, mmol/1 & $1.44 \pm 0.74$ & $1.38 \pm 0.70$ & $1.84 \pm 0.89$ & $<0.001$ \\
\hline LDL-cholesterol, mmol/1 & $3.56 \pm 1.02$ & $3.60 \pm 1.02$ & $3.66 \pm 1.07$ & 0.002 \\
\hline
\end{tabular}

Data are presented as mean \pm SD or $\%$

${ }^{\mathrm{a}} \chi^{2}$ and $t$ tests were used to assess differences for categorical and continuous measures across diabetes status association persisted (adjusted HR 1.67 [95\% CI 1.52, 1.83]). The increased risk of hospitalisation for infection associated with diabetes was observed for all subgroups and was stronger for Black participants and younger participants (Fig. 1, $p<0.05$ for interactions).

A similar association between diabetes and incident hospitalisation for infection was observed when modelling diabetes as a time-varying exposure (ESM Table 2) and after accounting for the competing risk of death (ESM Table 3). The adjusted rate of total hospitalisation for infection (including recurring events) was significantly higher in people with diabetes, overall (41 vs 25 per 1000 person-years, $p<0.001$ ) and across all subgroups (ESM Fig. 1).
In people with diabetes, rates of hospitalisation for specific types of infections ranged from 7.8 (respiratory infection) to 0.9 (postoperative infection) per 1000 person-years (Table 2). Those with diabetes had a significantly higher risk for hospitalisation for nearly every type of infection compared with people without diabetes. Differences persisted after adjustment for sociodemographic and health characteristics. The association was especially notable for foot infection (HR 5.99 [95\% CI 4.38, 8.19]).

There were 362 deaths for which infection was listed as the underlying cause (Table 3). After adjustment, the risk for infection mortality was significantly higher in people with 
Table 2 Association between diabetes status and risk of incident hospitalisation for infection, overall and across specific types of infection (the ARIC study, 1987-1989 to 2019)

\begin{tabular}{|c|c|c|c|c|c|c|c|c|c|}
\hline \multirow[t]{2}{*}{ Infection } & \multirow{2}{*}{$\begin{array}{l}\text { Events } \\
(n)\end{array}$} & \multirow{2}{*}{$\begin{array}{l}\text { Participants } \\
\text { (n) }\end{array}$} & \multirow{2}{*}{$\begin{array}{l}\text { Age-adjusted rate } \\
\text { per } 1000 \mathrm{PY} \\
(95 \% \mathrm{CI})\end{array}$} & \multicolumn{2}{|l|}{ Model $1^{\mathrm{a}}$} & \multicolumn{2}{|l|}{ Model $2^{\mathrm{b}}$} & \multicolumn{2}{|l|}{ Model $3^{c}$} \\
\hline & & & & $\begin{array}{l}\text { Adjusted HR } \\
(95 \% \text { CI })\end{array}$ & $p$ & $\begin{array}{l}\text { Adjusted HR } \\
(95 \% \mathrm{CI})\end{array}$ & $p$ & $\begin{array}{l}\text { Adjusted HR } \\
(95 \% \mathrm{CI})\end{array}$ & $p$ \\
\hline \multicolumn{10}{|l|}{ Any infection } \\
\hline No diabetes & 3597 & 10,894 & $15.2(14.8,15.7)$ & 1.00 (ref) & \multirow[t]{2}{*}{$<0.001$} & 1.00 (ref) & \multirow[t]{2}{*}{$<0.001$} & $1.00(\mathrm{ref})$ & \multirow[t]{2}{*}{$<0.001$} \\
\hline Diabetes & 632 & 1485 & $25.4(23.6,27.2)$ & $1.92(1.76,2.09)$ & & $1.88(1.72,2.05)$ & & $1.67(1.52,1.83)$ & \\
\hline \multicolumn{10}{|c|}{ Respiratory infection } \\
\hline No diabetes & 1314 & 10,894 & $5.3(5.0,5.6)$ & 1.00 (ref) & \multirow[t]{2}{*}{$<0.001$} & $1.00(\mathrm{ref})$ & \multirow[t]{2}{*}{$<0.001$} & $1.00(\mathrm{ref})$ & \multirow[t]{2}{*}{$<0.001$} \\
\hline Diabetes & 216 & 1485 & $7.8(6.8,8.9)$ & $1.65(1.42,1.91)$ & & $1.61(1.39,1.87)$ & & $1.49(1.28,1.74)$ & \\
\hline \multicolumn{10}{|c|}{ Urinary tract infection } \\
\hline No diabetes & 552 & 10,894 & $2.2(2.0,2.3)$ & 1.00 (ref) & \multirow[t]{2}{*}{$<0.001$} & 1.00 (ref) & \multirow[t]{2}{*}{$<0.001$} & $1.00(\mathrm{ref})$ & \multirow[t]{2}{*}{$<0.001$} \\
\hline Diabetes & 103 & 1485 & $3.7(3.0,4.4)$ & $1.98(1.60,2.46)$ & & $1.87(1.50,2.32)$ & & $1.58(1.26,1.98)$ & \\
\hline \multicolumn{10}{|l|}{ Foot infection } \\
\hline No diabetes & 97 & 10,894 & $0.4(0.3,0.4)$ & $1.00(\mathrm{ref})$ & \multirow[t]{2}{*}{$<0.001$} & 1.00 (ref) & \multirow[t]{2}{*}{$<0.001$} & $1.00(\mathrm{ref})$ & \multirow{2}{*}{$<0.001$} \\
\hline Diabetes & 99 & 1485 & $3.6(2.9,4.3)$ & $9.01(6.73,12.05)$ & & $8.31(6.19,11.15)$ & & $5.99(4.38,8.19)$ & \\
\hline \multicolumn{10}{|l|}{ GI infection } \\
\hline No diabetes & 285 & 10,894 & $1.1(1.0,1.2)$ & 1.00 (ref) & \multirow[t]{2}{*}{0.65} & 1.00 (ref) & \multirow[t]{2}{*}{0.48} & 1.00 (ref) & \multirow[t]{2}{*}{0.58} \\
\hline Diabetes & 30 & 1485 & $1.1(0.7,1.5)$ & $1.09(0.75,1.60)$ & & $1.15(0.78,1.68)$ & & $1.12(0.75,1.66)$ & \\
\hline \multicolumn{10}{|l|}{ Sepsis } \\
\hline No diabetes & 972 & 10,894 & $3.8(3.5,4.0)$ & 1.00 (ref) & \multirow[t]{2}{*}{$<0.001$} & 1.00 (ref) & \multirow[t]{2}{*}{$<0.001$} & $1.00(\mathrm{ref})$ & \multirow[t]{2}{*}{$<0.001$} \\
\hline Diabetes & 174 & 1485 & $6.2(5.4,7.1)$ & $2.28(1.94,2.69)$ & & $2.27(1.93,2.68)$ & & $1.92(1.62,2.28)$ & \\
\hline \multicolumn{10}{|c|}{ Postoperative infection } \\
\hline No diabetes & 103 & 10,894 & $0.4(0.3,0.5)$ & 1.00 (ref) & \multirow[t]{2}{*}{$<0.001$} & $1.00(\mathrm{ref})$ & $<0.001$ & $1.00(\mathrm{ref})$ & 0.007 \\
\hline Diabetes & 24 & 1485 & $0.9(0.5,1.2)$ & $2.78(1.76,4.38)$ & & $2.86(1.81,4.52)$ & & $1.95(1.20,3.15)$ & \\
\hline
\end{tabular}

${ }^{a}$ Model 1 adjusted for age, sex and race-centre

${ }^{\mathrm{b}}$ Model 2 adjusted for variables in model 1 plus SES, health insurance, smoking and alcohol consumption

${ }^{\mathrm{c}}$ Model 3 adjusted for variables in model 2 plus BMI, hypertension, chronic kidney disease, prevalent CHD status, HDL-cholesterol, triacylglycerols and LDL-cholesterol

GI, gastrointestinal; PY, person-years; ref, reference

diabetes (HR 1.72, [95\% CI 1.28, 2.31]). This increased risk was generally observed across all subgroups (ESM Fig. 2).

\section{Discussion}

In this prospective cohort study of middle-aged adults, we found that diabetes was significantly associated with an increased risk of hospitalisation for infection and infection mortality. These associations persisted after adjusting for demographic and cardiometabolic risk factors. The increased risk of hospitalisation for infection associated with diabetes was observed across major types of infections but was especially robust for foot infections.

Our findings are consistent with prior large prospective studies [5-9]. However, those studies had selected populations, short follow-up and/or limited adjustment for confounding. In contrast, our study population was a large communitybased sample of Black and White people, with over three decades of follow-up, detailed information on potential confounding factors and comprehensive ascertainment of diabetes status, hospitalisations and mortality. These features allowed for a uniquely rigorous assessment of risk of hospitalisation for infection and infection mortality associated with diabetes, overall and across a range of important subgroups. Our findings, along with results from prior reports, suggest that enhancing prevention and early treatment of infection in those with diabetes is needed to reduce infection-related morbidity and mortality.

Central to successful prevention of infection-related outcomes is the development of more comprehensive clinical guidance $[10,11]$. Current guidelines are limited, focusing primarily on the receipt of vaccinations (e.g. influenza and pneumonia) and foot ulceration screenings to prevent infection in people with diabetes [19]. Our findings support the emphasis of these preventive practices, as the absolute and relative risk of hospitalisation for respiratory or foot infections was significantly higher in people with diabetes. Nonetheless, 


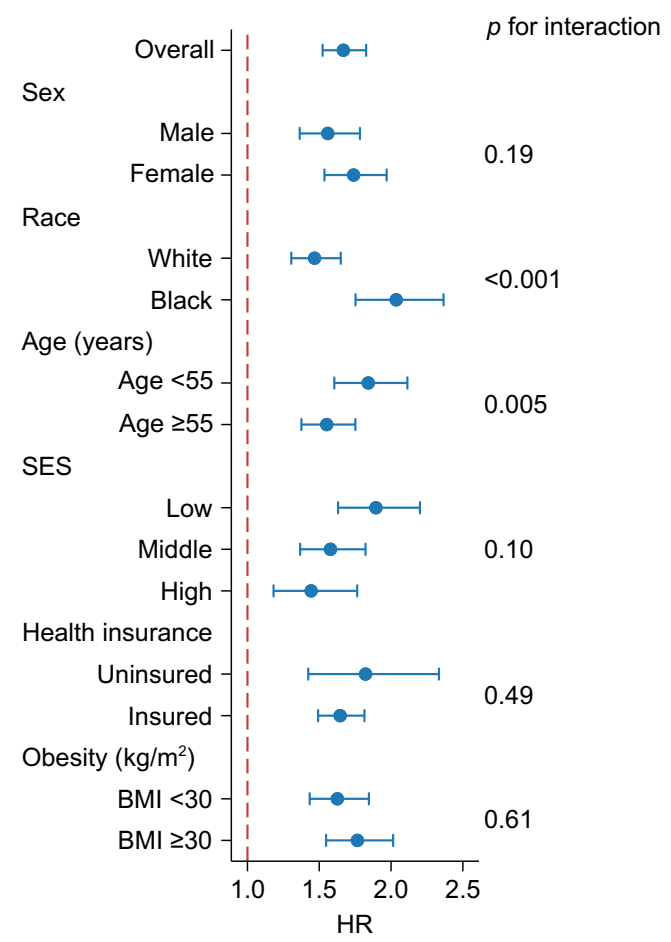

Fig. 1 Association of diabetes status with risk of incident hospitalisation for infection in subgroups of participants in the ARIC study, 1987-1989 to 2019. HRs (with 95\% CIs) are based on Cox models that adjusted for demographics (age, sex, race-centre, SES, insurance status), health behaviours (smoking, alcohol consumption) and cardiometabolic health (BMI, hypertension, chronic kidney disease, prevalent CHD status, HDLcholesterol, triacylglycerols and LDL-cholesterol)

we note that diabetes was associated with a higher risk for nearly every type of infection, as well as infection mortality, suggesting a need for broader guidance on infection prevention and management among those with diabetes. This is especially important given the emergence of the COVID-19 pandemic and the rising rates of hospitalisation for infection in the USA, both of which have disproportionately affected people with diabetes $[10,13]$.

Several mechanisms may explain the association between diabetes and infection. Hyperglycaemia is thought to impair the humoral and cell-mediated immune responses, thus increasing susceptibility to infection [1,2]. Diabetic complications, such as neuropathy and peripheral vascular disease, also increase the risk of specific types of infections (e.g. foot infections). Consistent with these mechanisms, emerging research shows a link between poor glycaemic control and infection-related outcomes in people with diabetes [11, 20-22]. These findings suggest that optimising glycaemic control may be important for infection prevention and management.

In exploratory analyses, we found that the association between diabetes and risk of incident hospitalisation for infection was stronger in younger individuals and in Black people. These differences may be driven partly by lower levels of engagement in recommended preventive practices, such as receipt of vaccinations [23, 24]. A higher burden of poor glycaemic control in these subgroups has also been noted [25]. Delayed access to care may also contribute, as young adults and racial/ethnic minorities are more likely to have unmet healthcare needs, even after accounting for health insurance status [26]. Our results suggest that targeted efforts aimed at improving patient education, timely access to care and diabetes control may reduce infection morbidity in highrisk groups. However, further research is needed to confirm whether race and age modify the association between diabetes and infection complications.

Our study had several limitations. First, our definition of hospitalisation for infection has not been validated by medical record review. Second, because infections were ascertained from hospital discharge records, we likely missed milder cases of infection. Nonetheless, infections requiring hospitalisation are clinically significant because they carry a high burden of morbidity and mortality. Third, $\mathrm{HbA}_{1 \mathrm{c}}$ was not measured at the baseline study visit, preventing us from examining the association between glycaemic control and infection complications. Fourth, there may be ascertainment bias, as physicians may be more prone to referring individuals with diabetes to hospitals (rather than outpatient settings) to address infections. Fifth, we were unable to determine whether participants had type 1 or type 2 diabetes. However, type 1 diabetes only

Table 3 Association between diabetes and the risk of infection mortality

\begin{tabular}{|c|c|c|c|c|c|c|c|c|c|}
\hline \multirow[t]{2}{*}{ Diabetes status } & \multirow{2}{*}{$\begin{array}{l}\text { Events } \\
(n)\end{array}$} & \multirow{2}{*}{$\begin{array}{l}\text { Participants } \\
(n)\end{array}$} & \multirow{2}{*}{$\begin{array}{l}\text { Age-adjusted rate per } \\
1000 \text { PY }(95 \% \text { CI })\end{array}$} & \multicolumn{2}{|l|}{ Model $1^{\mathrm{a}}$} & \multicolumn{2}{|l|}{ Model $2^{\mathrm{b}}$} & \multicolumn{2}{|l|}{ Model $3^{\mathrm{c}}$} \\
\hline & & & & $\begin{array}{l}\text { Adjusted HR } \\
(95 \% \mathrm{CI})\end{array}$ & $p$ & $\begin{array}{l}\text { Adjusted HR } \\
(95 \% \mathrm{CI})\end{array}$ & $p$ & $\begin{array}{l}\text { Adjusted HR } \\
(95 \% \mathrm{CI})\end{array}$ & $p$ \\
\hline No diabetes & 301 & 10,894 & $1.2(1.0,1.3)$ & 1.00 (ref) & $<0.001$ & $1.00(\mathrm{ref})$ & $<0.001$ & $1.00(\mathrm{ref})$ & $<0.001$ \\
\hline Diabetes & 61 & 1485 & $2.1(1.6,2.7)$ & $2.01(1.52,2.67)$ & & $2.00(1.50,2.65)$ & & $1.72(1.28,2.31)$ & \\
\hline
\end{tabular}

${ }^{a}$ Model 1 adjusted for age, sex and race-centre

${ }^{\mathrm{b}}$ Model 2 adjusted for variables in model 1 plus SES, insurance health, smoking and alcohol consumption

${ }^{\mathrm{c}}$ Model 3 adjusted for variables in model 2 plus BMI, hypertension, chronic kidney disease, prevalent CHD status, HDL-cholesterol, triacylglycerols and LDL-cholesterol

PY, person-years; ref, reference 
makes up $~ 5 \%$ of all cases in the USA [27]. Therefore, our results likely reflect the potential risk for infection complications conferred by type 2 diabetes. Sixth, while we included a rich set of rigorously measured covariates, residual confounding is a concern in any observational study. For instance, we did not have information on chronic infections (e.g. hepatitis), which may be more common in people with diabetes [28]. Related to this, there may also be residual confounding because factors such as BMI or BP can change over time; we only adjusted for these risk factors at baseline.

In conclusion, diabetes was independently associated with an increased risk of hospitalisation for infection. This association was observed across most major types of infection and was more pronounced for younger people and Black people. The risk of infection mortality was elevated for those with diabetes compared with those without diabetes. More comprehensive clinical guidance to improve infection-related preventive measures and early treatment of infection may reduce related morbidity and mortality in people with diabetes.

Supplementary Information The online version of this article (https:// doi.org/10.1007/s00125-021-05522-3) contains peer-reviewed but unedited supplementary material.

Acknowledgements The authors thank the staff and participants of the ARIC study for their important contributions.

Data availability The ARIC data analysed are not publicly available due to confidentiality issues. Investigators can access data from the ARIC study by submitting a manuscript proposal to aricpub@unc.edu.

Funding MF is supported by National Institutes of Health/National Heart, Lung, and Blood Institute grant T32 HL007024. ES is supported by National Institutes of Health/National Heart, Lung, and Blood Institute grant K24 HL152440 and National Institutes of Health/National Institute of Diabetes and Digestive and Kidney Diseases grant R01 DK089174. JBE-T is supported by National Institutes of Health/National Heart, Lung, and Blood Institute grant K23 HL153774. The ARIC study has been funded in whole or in part with Federal funds from the National Heart, Lung, and Blood Institute, National Institutes of Health, Department of Health and Human Services, under Contract nos HHSN268201700001I, HHSN268201700002I, HHSN268201700003I, HHSN268201700005I, HHSN268201700004I. The study sponsors/funders were not involved in the design of the study, the collection, analysis and interpretation of data, writing the report, and the decision to submit the paper for publication, and did not impose any restrictions regarding the publication of the report.

Authors' relationships and activities ES is an Associate Editor for Diabetologia and had no role in peer-review of the manuscript. All other authors declare that there are no relationships or activities that might bias, or be perceived to bias, their work.

Contribution statement MF and ES designed the study. MF conducted the statistical analysis. ES guided the statistical analysis. MF drafted the manuscript. All authors provided substantial contributions to the interpretation of data, made critical revisions to the manuscript and approved the final manuscript. MF is the guarantor of this work and, as such, had full access to all the data in the study, controlled the decision to publish, and takes responsibility for the integrity of the data and the accuracy of the data analysis. The corresponding author, ES, attests that all listed authors meet authorship criteria and that no others meeting the criteria have been omitted.

\section{References}

1. Joshi N, Caputo GM, Weitekamp MR, Karchmer A (1999) Infections in patients with diabetes mellitus. NEJM 341(25): 1906-1912. https://doi.org/10.1056/NEJM199912163412507

2. Casqueiro J, Casqueiro J, Alves C (2012) Infections in patients with diabetes mellitus: A review of pathogenesis. Indian J Endocr Metab 16(Supp11):S27-S36

3. Knapp S (2013) Diabetes and infection: Is there a link? A minireview. Gerontology 59(2):99-104. https://doi.org/10.1159/ 000345107

4. Abu-Ashour W, Twells L, Valcour J et al (2017) The association between diabetes mellitus and incident infections: a systematic review and meta-analysis of observational studies. BMJ Open Diabetes Res Care 5(1):e000336. https://doi.org/10.1136/bmjdrc2016-000336

5. Shah BR, Hux JE (2003) Quantifying the risk of infectious diseases for people with diabetes. Diabetes Care 26(2):510-513. https://doi. org/10.2337/diacare.26.2.510

6. Carey IM, Critchley JA, DeWilde S, Harris T, Hosking FJ, Cook DG (2018) Risk of infection in type 1 and type 2 diabetes compared with the general population: a matched cohort study. Diabetes Care 41(3):513-521. https://doi.org/10.2337/dc17-2131

7. Benfield T, Jensen J, Nordestgaard B (2007) Influence of diabetes and hyperglycaemia on infectious disease hospitalisation and outcome. Diabetologia 50(3):549-554. https://doi.org/10.1007/ s00125-006-0570-3

8. Magliano DJ, Harding JL, Cohen K, Huxley RR, Davis WA, Shaw JE (2015) Excess risk of dying from infectious causes in those with type 1 and type 2 diabetes. Diabetes Care 38(7):1274-1280. https:// doi.org/10.2337/dc14-2820

9. Bertoni AG, Saydah S, Brancati FL (2001) Diabetes and the risk of infection-related mortality in the US. Diabetes Care 24(6):10441049. https://doi.org/10.2337/diacare.24.6.1044

10. Harding JL, Benoit SR, Gregg EW, Pavkov ME, Perreault L (2020) Trends in Rates of Infections Requiring Hospitalization Among Adults With Versus Without Diabetes in the US, 2000-2015. Diabetes Care 43(1):106-116

11. Pearson-Stuttard J, Blundell S, Harris T, Cook DG, Critchley J (2016) Diabetes and infection: assessing the association with glycaemic control in population-based studies. Lancet Diabetes Endocrinol 4(2):148-158. https://doi.org/10.1016/S2213-8587(15) 00379-4

12. Selvin E, Juraschek SP (2020) Diabetes Epidemiology in the COVID-19 Pandemic. Diabetes Care 43(8):1690-1694. https:// doi.org/10.2337/dc20-1295

13. Fang M, Wang D, Tang O, Selvin E (2020) Prevalence of Chronic Disease in Laboratory-Confirmed COVID-19 Cases and US Adults (2017-2018). Diabetes Care 43(10):e127-e128. https://doi.org/10. 2337/dc20-1640

14. ARIC Investigators (1989) The Atherosclerosis Risk in Communities (ARIC) study: design and objectives. Am J Epidemiol 129(4):687-702. https://doi.org/10.1093/ oxfordjournals.aje.a115184 
15. Ishigami J, Grams ME, Chang AR, Carrero JJ, Coresh J, Matsushita $\mathrm{K}$ (2017) CKD and risk for hospitalization with infection: the Atherosclerosis Risk in Communities (ARIC) Study. Am J Kidney Dis 69(6):752-761. https://doi.org/10.1053/j.ajkd.2016. 09.018

16. Singh GK (2003) Area deprivation and widening inequalities in US mortality, 1969-1998. Am J Public Health 93(7):1137-1143. https://doi.org/10.2105/AJPH.93.7.1137

17. Levey AS, Stevens LA, Schmid CH et al (2009) A new equation to estimate glomerular filtration rate. Ann Intern Med 150(9):604 612. https://doi.org/10.7326/0003-4819-150-9-200905050-00006

18. Zou G (2004) A modified poisson regression approach to prospective studies with binary data. Am J Epidemiol 159(7):702-706. https://doi.org/10.1093/aje/kwh090

19. American Diabetes Association (2021) Standards of Medical Care in Diabetes-2021. Diabetes Care 44(Supp 1):S1-S225

20. Schneider AL, Kalyani RR, Golden S et al (2016) Diabetes and prediabetes and risk of hospitalization: the Atherosclerosis Risk in Communities (ARIC) Study. Diabetes Care 39(5):772-779. https:// doi.org/10.2337/dc15-1335

21. Zacay G, Sikron FH, Heymann AD (2020) Glycemic Control and Risk of Cellulitis. Diabetes Care 44(2):367-372

22. Kornum JB, Thomsen RW, Riis A, Lervang H-H, Schønheyder HC, Sørensen HT (2008) Diabetes, glycemic control, and risk of hospitalization with pneumonia: a population-based case-control study. Diabetes Care 31(8):1541-1545. https://doi.org/10.2337/ dc08-0138

23. Saydah SH (2018) Medication use and self-care practices in persons with diabetes. National Institutes of Health, Bethesda, MD

24. Fang M, Echouffo Tcheugui JB, Pankow JS, Windham BG, Selvin E (2020) Patient-reported preventive care practices in older adults with diabetes. Diabetic Med e14508. https://doi.org/10.3724/SP.J. 1123.2019.10034

25. Casagrande SS, Fradkin JE, Saydah SH, Rust KF, Cowie CC (2013) The prevalence of meeting A1C, blood pressure, and LDL goals among people with diabetes, 1988-2010. Diabetes Care 36(8):2271-2279. https://doi.org/10.2337/dc12-2258

26. Ayanian JZ, Weissman JS, Schneider EC, Ginsburg JA, Zaslavsky AM (2000) Unmet health needs of uninsured adults in the United States. JAMA 284(16):2061-2069. https://doi.org/10.1001/jama. 284.16.2061

27. Xu G, Liu B, Sun Y et al (2018) Prevalence of diagnosed type 1 and type 2 diabetes among US adults in 2016 and 2017: population based study. BMJ 362:k1497. https://doi.org/10.1136/bmj.k1497

28. Mehta SH, Brancati FL, Strathdee SA et al (2003) Hepatitis C virus infection and incident type 2 diabetes. Hepatology 38(1):50-56. https://doi.org/10.1053/jhep.2003.50291

Publisher's note Springer Nature remains neutral with regard to jurisdictional claims in published maps and institutional affiliations. 